\title{
Research on the relationship between Fresh Food E-commerce Consumption Experience and Customer Fit from the Perspective of Value Co-creatio
}

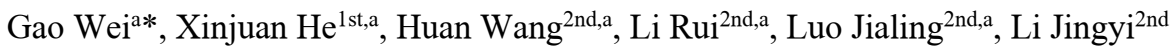 \\ ${ }^{a}$ Sichuan Agricultural University, Chengdu, China
}

\begin{abstract}
In recent years, the fresh food e-commerce platforms have been developing rapidly with facing increasingly fierce market competition. From the perspective of value co-creation, the core competitive advantage of enterprises in the future lies in creating unique values with customers. Starting from the perspective of innovation, this study explores the relationship fresh food e-commerce consumption experience and customer fit, so as to provide decision-making reference for the management of the platforms.
\end{abstract}

\section{Introduction}

In the context of the Internet, the change in the value co-creation logic has a dramatic effect on the business model, leading customer co-creation of value has become the key to business model innovation. Value not only lies in the value of the product or service itself, but also originates from the high quality fit of customers' consumption experience.

Focusing on the fresh food e-commerce market in China, the market size has exceeded 200 billion yuan in 2018 [1], with an average annual growth rate of more than $50 \%$ [2]. Fresh food e-commerce has the characteristics of large market size, high consumption frequency and rigid demand. Its future development is still promising [3]. In recent years, the fresh food e-commerce industry in China has developed rapidly, but due to the change in the value co-creation logic and the lack of consumer experience, it went through a two-year reshuffle period in 2016. Therefore, In this background, it is a big problem to improve the consumer experience of fresh food e-commerce and enhance their matching behavior for these companies now. Under the logic of value co-innovation, the issues, how to make the consumer experience of consumers achieve a high-quality fit and where to find an industry guidance method to adapt to the new situation, are urgent for these companies to be solved.

In view of this, this research selects the fresh food e-commerce market and explores the relationship between consumer experience and customer fit from the perspective of value co-creation, so as to provide decision support for fresh food e-commerce companies to better manage and use experience perception, so as to promote customers fit together to achieve value co-creation and two-way win-win eventually.

\section{Theory and Hypothesiss}

\subsection{Impact of consumer experience on customer fit}

The consumer experience originated from the book " Experience Economy " by American economists Joseph Payne and James Gilmore, which advocates that producers should create conditions for consumers to integrate into the supply chain and make consumers willing to feel outside the product. Paying. The consumer experience includes not only the consumer's feelings when purchasing the product, but also the consumer's information search before purchasing and the post-purchase usage experience. All links with the consumer are part of the consumer experience. According to the above, the definition of consumer experience above, combined with the characteristics of e-commerce platforms, this study divides consumer experience into functional experience, emotional experience, and relationship experience.

The rapid development of network technology has spawned the emergence of a series of new media, making the interaction between customers and enterprises more and more tight and diversified, and the impact of customers' non-purchasing behaviors on enterprises has been increasing [4]. Some scholars have put forward a new concept "customer fit" in 2006. Since then, research on customer fit behavior has continued to emerge. Customer fit is an activity that can provide value to customers and enterprises at the same time [5], and has a significant positive effect on customer perceived value. Positive impact [6], And outstanding customer value is the basis for ensuring customer satisfaction and establishing customer loyalty, which is the fundamental

*Corresponding Author 
purpose of business operations [7]. The reason why companies have this purpose is to enhance their competitiveness to a large extent needs.

Cui Zheng, Zhao Mengqi, and Xu Zhongyue (2018) confirmed the positive relationship between consumer experience and customer fit through research on transactional virtual communities [8] .Li Wenyong, Tan Tonghui, and Liu Li (2018) are also pointed out that the customer experience has a positive impact on the formation of customer engagement [9] while studying the user relationship of the tourism website.

Based on the above theory and analysis, this study proposes the following hypotheses:

Hypothesis h1: Customer consumption experience has a positive impact on customer fit.

\section{2 the impact of consumer experience on value co-creation}

Co-creation of value is a new field of agricultural product marketing research. The Internet has overturned the way of value creation, and now value creation and consumers are getting closer and closer. With the gradual improvement of consumers' demand and cognition, customers' perception of experience has gradually joined in the value creation of the enterprise. Then companies create resources by interacting with customers to create value, and meet the needs of consumers to enhance core competitiveness. In the online shopping environment of agricultural products, customer participation in value co-creation is more complex. Value co-creation also includes value co-creation between enterprises and customers, and also between customers and customers. Therefore, this article divides value co-creation into spontaneous value co-creation and initiated value co-creation according to the classification of Zwass [10].

Based on the above theory and analysis, this study proposes the following hypotheses:

Hypothesis H2a: The customer consumption experience has a significant positive impact on the spontaneous value creation of the company;

Hypothesis H2b: The customer consumption experience has a significant positive impact on the creation of value co-creation.

\section{3 the impact of value co-creation on customer fit}

During the process of customer participation in value co-creation, the company recognized the customer's preferences and styles through information transmission. While the company obtained customer resources, customers also deepened their awareness of the company and brand in the process of participation, which further promotes Customer fit. Based on the theory of customer fit and value co-creation, Jian Zhaoquan and Linghu Kerry (2018) adopted the method of case study and took the Xiaomi community as the research object to explore the influence mechanism of customer fit on the value co-creation of the virtual brand community [11]. The research model reveals that the virtual brand community is a typical platform for value co-creation, and value co-creation is achieved through a systematic process of "motivation-process-result." Tu Jianbo, Tao Xiaobo, Yang Yiweng (2018) constructed the model of service scenario, customer fit,co-creation value and purchase intention[12].

Based on the above theory and analysis, this study proposes the following hypotheses:

Hypothesis H3a: The company's spontaneous value co-creation has a significant positive impact on customer fit;

Hypothesis $\mathrm{H} 3 \mathrm{~b}$ : Initiating value co-creation has a significant positive impact on customer fit.

\subsection{Intermediary role of value co-creation}

In recent years, the fresh food e-commerce industry in China has developed rapidly, but due to the lack of consumer experience, it experienced a two-year reshuffle period in 2016. Under this background, how to increase the experience perception of fresh food e-commerce users has become a big problem for the fresh e-commerce industry to solve. Difficulties facing the fresh e-commerce industry. At the same time, according to Zhang et al., customer fit is the core of interactive experience and value co-creation [13]. Therefore, how can fresh e-commerce companies improve their value through co-creation with consumers? Matching behavior is also an urgent issue.

To sum up, in this study, fresh e-commerce market is selected, and from the perspective of value co-creation, experience perception and matching behavior are combined to find out the connection between experience perception and customer fit, so as to provide decision support for fresh e-commerce to better manage and use experience perception, so as to make more scientific management decision and realize value co-creation and two-way win-win.

Based on the above theory and analysis, this study proposes the following hypotheses:

Hypothesis H4a: Spontaneous value co-creation plays a mediating role in the impact of consumer experience on customer fit;

Hypothesis H4b: Initiating value co-creation plays an intermediary role in the impact of consumer experience on customer fit.

Based on the above Hypothesiss, the theoretical model proposed in this study is shown in the following figure:

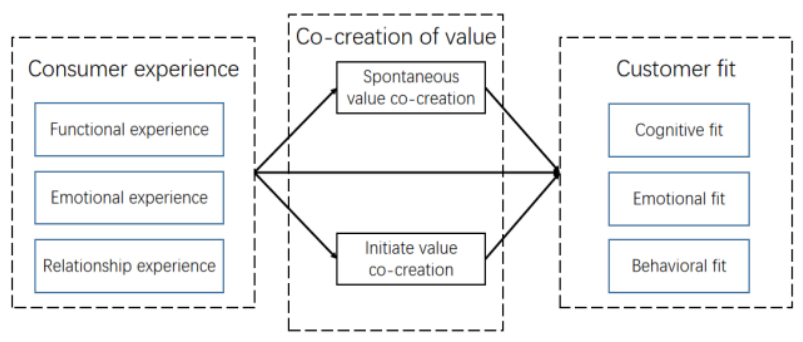

Figure 1. Research model diagram 


\section{Research design}

\subsection{Data collection}

This study studies the relationship between fresh e-commerce consumption experience and customer fit from the perspective of value co-creation, taking fresh e-commerce users as the research object. Before the questionnaire was issued, the author modified the original questionnaire based on expert opinions, and then referred to the preliminary survey results. The survey results adjusted the content of the questionnaire. In November 2019, by issuing an online questionnaire in the comment area of the fresh e-commerce platform, the author collected a total of 347 questionnaires, of which 315 were valid questionnaires, with an effective rate of $90.78 \%$.

Table 1 Scale measurement items and reliability and validity tests

\begin{tabular}{|c|c|c|c|c|c|c|c|c|c|c|c|}
\hline \multicolumn{2}{|c|}{ variable } & $\begin{array}{c}\text { Measure } \\
\text { item }\end{array}$ & Estimate & S.E. & $P$ & $\mathrm{SMC}$ & 1-SMC & C.R. & CITC & AVE & $\begin{array}{c}\text { Cronbach } \\
\alpha\end{array}$ \\
\hline \multirow{10}{*}{$\begin{array}{l}\text { Consumer } \\
\text { experience }\end{array}$} & \multirow{4}{*}{$\begin{array}{l}\text { Functional } \\
\text { experience }\end{array}$} & Q1_1 & 1.000 & & & .725 & .275 & & .768 & \multirow{4}{*}{.751} & .892 \\
\hline & & Q1_2 & 1.035 & .085 & $* * *$ & .774 & .226 & 12.239 & .798 & & \\
\hline & & Q1_3 & 1.003 & .085 & $* * *$ & .754 & .246 & 11.854 & .780 & & \\
\hline & & Q1_4 & .986 & .084 & $* * *$ & .752 & .248 & 11.736 & .705 & & \\
\hline & \multirow{3}{*}{$\begin{array}{l}\text { Emotional } \\
\text { experience }\end{array}$} & Q2_1 & .833 & .084 & $* * *$ & .672 & .328 & 9.925 & .632 & \multirow{3}{*}{.724} & \multirow{3}{*}{.813} \\
\hline & & Q2_2 & .798 & .078 & $* * *$ & .729 & .271 & 10.253 & .666 & & \\
\hline & & Q2_3 & .957 & .081 & $* * *$ & .770 & .230 & 11.786 & .692 & & \\
\hline & \multirow{3}{*}{$\begin{array}{l}\text { Relationship } \\
\text { experience }\end{array}$} & Q3_1 & .819 & .091 & $* * *$ & .573 & .427 & 9.010 & .622 & \multirow{3}{*}{.567} & \multirow{3}{*}{.781} \\
\hline & & Q3_2 & .885 & .094 & $* * *$ & .565 & .435 & 9.425 & .647 & & \\
\hline & & Q3_3 & .871 & .094 & $* * *$ & .563 & .437 & 9.310 & .587 & & \\
\hline \multirow{3}{*}{\multicolumn{2}{|c|}{$\begin{array}{l}\text { Spontaneous value } \\
\text { co-creation }\end{array}$}} & Q4_1 & 1.000 & & $x$ & .747 & .253 & & .709 & \multirow{3}{*}{.661} & .798 \\
\hline & & Q4_2 & 1.185 & .099 & $* * *$ & .782 & .218 & 12.016 & .672 & & \\
\hline & & Q4_3 & .861 & .096 & $* * *$ & .455 & .545 & 8.929 & .544 & & \\
\hline \multirow{3}{*}{\multicolumn{2}{|c|}{ Initiate value co-creation }} & Q5_1 & 1.000 & & + & .574 & .426 & & .631 & \multirow{3}{*}{.655} & .788 \\
\hline & & Q5_2 & 1.047 & .117 & $* * *$ & .620 & .380 & 8.978 & .664 & & \\
\hline & & Q5_3 & .919 & .100 & $* * *$ & .770 & .230 & 9.200 & .593 & & \\
\hline \multirow{9}{*}{$\begin{array}{l}\text { customer } \\
\text { fit }\end{array}$} & \multirow{3}{*}{$\begin{array}{c}\text { Cognitive } \\
\text { fit }\end{array}$} & Q6_1 & 1.000 & & 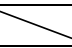 & .628 & .372 & & .771 & \multirow{3}{*}{.668} & .883 \\
\hline & & Q6_2 & 1.072 & .090 & $* * *$ & .705 & .295 & 11.883 & .796 & & \\
\hline & & Q6_3 & .990 & .088 & $* * *$ & .672 & .328 & 11.239 & .750 & & \\
\hline & \multirow{3}{*}{$\begin{array}{c}\text { Emotional } \\
\text { fit }\end{array}$} & Q7_1 & .785 & .072 & $* * *$ & .769 & .231 & 10.934 & .685 & \multirow{3}{*}{.719} & \multirow{3}{*}{.859} \\
\hline & & Q7_2 & .802 & .078 & $* * *$ & .689 & .311 & 10.243 & .760 & & \\
\hline & & Q7_3 & .905 & .082 & $* * *$ & .699 & .301 & 10.997 & .762 & & \\
\hline & \multirow{3}{*}{$\begin{array}{c}\text { Behavioral } \\
\text { fit }\end{array}$} & Q8_1 & .930 & .090 & $* * *$ & .590 & .410 & 10.294 & .639 & \multirow{3}{*}{.534} & \multirow{3}{*}{.767} \\
\hline & & Q8_2 & .809 & .090 & $* * * *$ & .506 & .494 & 8.947 & .622 & & \\
\hline & & Q8_3 & .801 & .090 & $* * *$ & .506 & .494 & 8.888 & .542 & & \\
\hline
\end{tabular}

\subsection{Model setting and variable measurement}

This research model consists of four parts: consumer experience, spontaneous value co-creation, initiated value co-creation, and customer fit. Value co-creation is introduced as an intermediary factor between consumer experience and customer fit to explore the relationship between fresh e-commerce consumption experience and customer fit from the perspective of value co-creation.

The questionnaire in this article is set with reference to the maturity scales proposed in previous studies. The consumption experience draws on the scales of Mittal and J. Josko Brakus [14], and sets 10 items in total. Spontaneous value co-creation and initiated value co-creation refer to the scale proposed by Zwass [10], and set up 6 items in total. And the customer fit refers to the scale of Hollebeek [15] and has a total of 9 items. Each scale option uses a Likert five-level scale to set.

\section{Empirical analysis}

\subsection{Reliability and validity analysis}

This study uses Cronbach's Alpha coefficient for reliability test. The test results are shown in Table 1 . The scale involves 4 variables and 25 items, of which the consumer experience is divided into three dimensions: functional experience, emotional experience and relationship experience and the costumer fit is divided into three dimension: cognitive fit, emotional fit and behavioral fit. After credibility tests, the Cronbach's Alpha coefficients of the three dimensions of consumer experience, the three dimensions of customer experience, the spontaneous value co-creation and the initiated value co-creation are all greater than 0.7, Proving that the reliability of the questionnaire is good. After the validity test, the combined reliability $\mathrm{CR}$ value of the dimensions of the consumer experience and customer, the spontaneous value co-creation and the initiation value 
co-creation are all greater than 0.7 , and the average extraction variance value AVE is greater than 0.5. To sum up, the validity of the questionnaire is good.

\subsection{Hypothesis test}

This research uses amos 22.0 to conduct a hypothesis test analysis to verify the two-factor intermediary effect. First, the direct impact of consumer experience on customer fit is verified, and then the relationship between consumer experience and customer fit is examined from the perspective of value co-creation. When $p$ is less than 0.001 , The impact of the two is particularly significant. The model of the verification result is shown in the following figure.

It can be seen from Figure 2 that the standardized path coefficient value of consumer experience to customer fit is $0.51, \mathrm{p}<0.001$. Therefore, consumer experience has a significant positive impact on customer fit. $\mathrm{H} 1$ is verified.

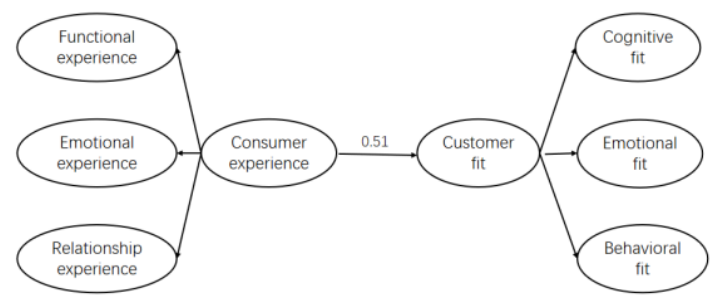

Figure 2 Effect model of consumer experience and customer fit

It can be seen from Figure 3 that the standardized path coefficient value of consumer experience to spontaneous value co-creation is $0.59, \mathrm{P}<0.001$. Therefore, consumer experience has a significant positive impact on spontaneous value co-creation. H2a is verified. The standardized path coefficient value of consumer experience to initiate value co-creation is 0.53 , $\mathrm{P}<0.001$. Therefore, consumer experience has a significant positive impact on initiate value co-creation. $\mathrm{H} 2 \mathrm{~b}$ is verified.

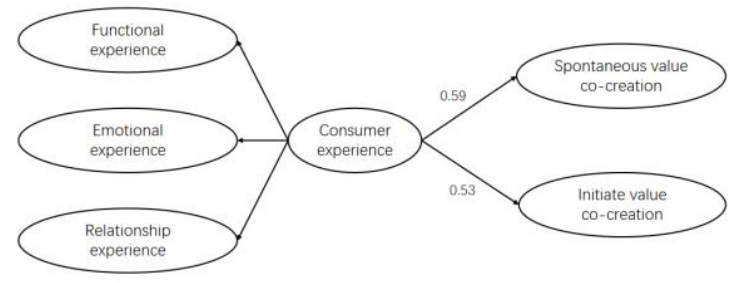

Figure 3 Consumption experience and value co-creation model

It can be seen from Figure 4 that the standardized path coefficient value of spontaneous value co-creation to customer fit is $0.47, \mathrm{P}<0.001$. Therefore, spontaneous value co-creation has a significant positive impact on customer fit. $\mathrm{H} 3 \mathrm{a}$ is verified. The standardized path coefficient value of initiate value co-creation to customer fit is $0.29, \mathrm{P}<0.001$. Therefore, initiate value co-creation has a significant impact on consumer fit. $\mathrm{H} 3 \mathrm{~b}$ is verified.

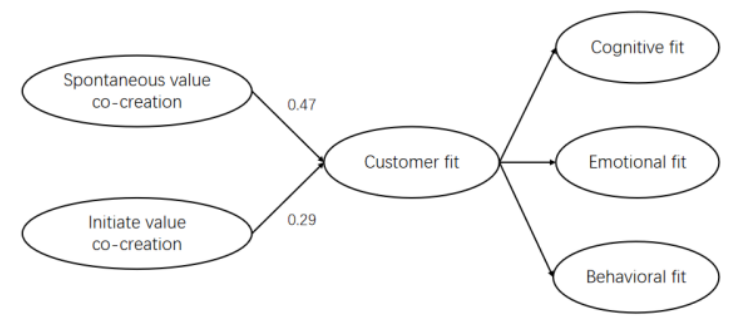

Figure 4 Co-creation model of value co-creation and customers

From the structural equation model in Figure 5, it can be seen that the customer experience has a significant positive effect on spontaneous value co-creation, the customer consumption experience has a significant positive impact on the initiate value co-creation, and the customer consumption experience also has a significant positive impact on customer fit. The equation indicates that after adding value co-creation, the direct impact of customer consumption experience on customer fit becomes smaller $(0.39<0.92)$, and at the same time, the impact of customer consumption experience on customer fit is significant, so spontaneous value co-creation and initiate value co-creation play an intermediary role in the relation between consumer experience and customer fit, which verifies the $\mathrm{H} 4 \mathrm{a}$ and $\mathrm{H} 4 \mathrm{~b}$ hypotheses.

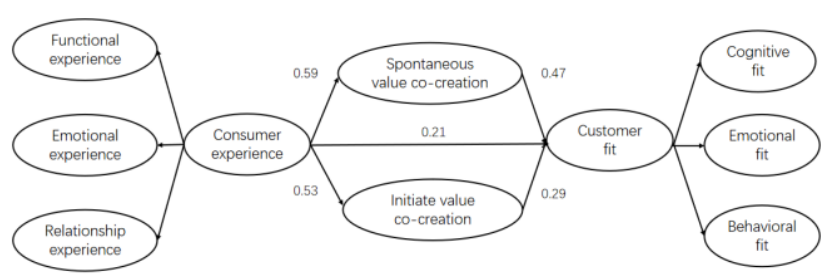

Figure 5 Intermediary model of value co-creation

\section{Conclusions and inspiration}

\subsection{Analysis conclusion}

Fresh consumer e-commerce consumer experience has a significant positive impact on spontaneous value co-creation and initiate value co-creation. Under the conditions of fresh consumer e-commerce platform management and extensive user participation, the optimization of consumer experience will promote customers and companies to further initiate value co-creation behavior.

Spontaneous value co-creation and initiate value co-creation are positively affecting customer fit. Value co-creation is of great significance to promote the improvement of customer fit.

Value co-creation conducts the impact of consumer experience on customer fit. Spontaneous value co-creation and initiate value co-creation play an intermediary role in the impact of consumer experience on customer fit. 


\subsection{Management inspiration}

The fresh e-commerce market is highly competitive, and companies will try their best to improve their competitiveness. Enterprise competitiveness depends on the degree of customer recognition of the value of the company's products or services. The perceived value of customers determines the company's competitive advantage [16]. The value of customer experience is One of the important influencing factors of perceived value of online consumption [17]. Schneider (2004) pointed out that the core competitive advantage of future enterprises lies in creating unique value with customers [18]; Zhang et al. (2017) pointed out in the research that customer fit is the core of interactive experience and value co-creation, and customer fit may have a positive effect on customer value creation [19]. Those just illustrates the close connection between customer fit, user experience and value co-creation. The study also verified the relationship between consumer experience and customer fit from the perspective of value co-creation from an empirical perspective.

With the increasing influence of customers' non-purchasing behaviors on enterprises [20], the relationship between customers and enterprises has been continuously strengthened, and value creation has shifted from enterprise-led to consumer-led [21]. Customer perceived value determines the competitive advantage of enterprises [22]. Fresh food e-commerce enterprises should continuously improve their products and services, spontaneously carry out value creation activities, improve the quality of platform services, stimulate consumers' motivation to create value, and work with customers to create unique value, thereby improving health Fresh e-commerce users' willingness to behave has reach a positive level of customer fit.

\section{References}

[1] Yunge Data. 2018 China Mobile Internet Industry Review Report [r]. Yunge Data, 2019.

[2] iResearch. 2018 China's Fresh Food E-commerce Industry Consumption Insight Report [r]. IResearch, 2019: 4.

[3] China Commercial Industry Research Institute. 2018 China Fresh Food E-commerce Industry Research Report [r]. China Commercial Industry Research Institute, 2019.

[4] BijmoltT.H.A. , LeeflangP.S.H. , BlockF. , eta1Analytics for customer fit[J].Journal of Service Research, 2010, 13(3) : 341-356.

[5] Jing Ningning, Li Defeng. Review of customer fit research [j]. Foreign Economy and Management, 2015, 37 (7): 33-45.

[6] Han Xiaoyun, Hu Lin, Zhang Xuwen. The impact of customer fit in virtual community on customer co-creation value [j]. Service Science and Management, 2016, 5 (3): 94-107.

[7] Bai Changhong, Fan Xiucheng, Gan Yuan. Brand Management of Service Enterprises Based on
Customer Perceived Value [j]. Foreign Economy and Management, 2002, 24 (2): 7-13.

[8] Cui Zheng, Zhao Mengqi, Xu Zhongyue. Research on the Impact of Customer Experience of Transactional Virtual Community on customer fit [j]. Monthly Price Journal, 2018 (09): 64-69.

[9] Li Wenyong, Tan Tonghui, Liu Li. Research on the relationship between "experience perception and fit behavior" of travel website users: based on the perspective of value co-creation [j]. Science \& Technology Innovation and Application, 2018 (26): $42-44+46$.

[10] ZwassV.Co-creation:Toward a taxonomy and an integrated research perspective[J].International Journal of Electronic Commerce,2010,15(1).

[12] Jian Zhaoquan, Ling $\mathrm{Hu}$ Kerui. The Impact Mechanism of Customer Coordination of Virtual Brand Community on Value Co-creation [j]. Chinese Journal of Management, 2018 (3): 326-334.

[13] Tu Jianbo, Tao Xiaobo, Yang Yiweng. Service scenarios, co-creation value and purchase willingness of shopping websites - the mediation effect of customer fit [j]. Finance and Economics Journal, 2018 (12): 95-104.

[14] Zhang M., Guo L., Hu M., et al. Influence of customer fit with Company Social Networks on Stickness : Mediating Effect of Customer Value Creation[J]. International Journal of Information Management,201737:229-240.

[15] Brakus, J. Joško, Schmitt B H , Zarantonello L . Brand Experience: What is It? How is it Measured? Does it Affect Loyalty?[J]. Journal of Marketing, 2009, 73(3):52-68.

[16] Hollebeek L D.Demystifying customer brand engagement : Exploring the loyalty nexus [J ]. Journal of Marketing Management, 2011, 27 (78) : 785- 807.

[17] Fan Xiucheng, Luo Haicheng. Analysis on the competitiveness of service enterprises based on customer perceived value [j]. Nankai Management Review, 2003, 6 (6): 41-45.

[18] Dubinsky A J.A Conceptual Model of Perceived Customer Value in E-commerce:A Preliminary Investigation[J].Psychology Marketing,2003,30(4):362.

[19] Schneider P A.The Future of Competition: Co-creating Unique Value with Customers [J].Academy of Management Executive,2004,18 (3):155-157.

[20] Zhang M., Guo L., Hu M., et al. Influence of customer fit with Company Social Networks on Stickness : Mediating Effect of Customer Value Creation[J]. International Journal of Information Management,201737:229-240.

[21] BijmoltT.H.A., , LeeflangP.S.H. , BlockF. , eta1Analytics for customer fit[J].Journal of Service Research, 2010, 13(3) : 341-356. 
[22] Zhao Zhe, Jia Wei, Cheng Peng, et al. Research on the Service Innovation and Value Co-creation Realization Mechanism of Vertical E-commerce-Based on the Perspective of
Service Leading Logic [J]. Journal of Dalian University of Technology (Social Science Edition), 2017 (04): 68-77. 